\title{
Comunicaciones
}

\section{DEL LIBERALISMO NOTABILIAR A LA "DEMOCRACIA DEFERENGIAL" \\ Algunas RefLeXIONES RESPECTO DEL DEBATE hiSTÓRICO SOBRE LAS TRANSFORMACIONES DEL SISTEMA * POLÍTICO OCCIDENTAL DURANTE EL SIGLO XIX}

\author{
AlBerto R. LetTIERI
}

\section{Los sistemas liberales notabiliares y las prácticas políticas}

Tradicionalmente los estudios canónicos sobre el sistema político moderno tendieron a caracterizar como "restringidos" a los sistemas basados en el censo o el sufragio limitado, por contraposición con aquellos en los cuales imperaba el sufragio universal. Esta clasificación, que alcanzó en nuestro siglo una hegemonía incuestionada a partir de los procesos de reconstrucción de las democracias europeas de la segunda posguerra, a menudo se complementaba con otra que, tomando como referente principal al "majority system" anglo-francés - del cual extraía procedimientos y estructuras modélicos-, permitía clasificar como de baja o mediana intensidad a los procesos desarrollados en la mayoría de los países occidentales, calificando como "desviaciones" a los requisitos no cumplidos exigidos por el esquema original. En algunos casos, como el de los sistemas latinos, incluso llegaría a sostenerse la inaplicabilidad del modelo liberal, describiéndose regularmente a algunos de sus comportamientos característicos - como lo que se consideraba un alto nivel de "corrupción" o una práctica desembozada de la "influencia"- de manera irónica e incluso caricaturesca.

Sin embargo durante los últimos años esas lecturas han sido puestas en cuestión, en particular a partir de la proliferación de estudios sobre las prácticas electorales en los sistemas liberales decimonónicos latinos. Por ejemplo, al considerar el carácter "restringido" de los sistemas de base censitaria, Antonio Annino y Rafaelle Romanelli han llamado la

- Este trabajo ha sido elaborado en el seno del seminario de doctorado "La política de la democracia. Procesos sociales de su construcción en el mundo occidental, 1789-1914" dictado por el Profesor Luis Alberto Romero en la Facultad de Filosofia y Letras (UBA), durante el segundo cuatrimestre de 1995. Deseo agradecer al profesor Romero sus interesantes comentarios.

* Ubacyt/Pehesa/Facultad de Filosofia y Letras/Universidad de Buenos Aires. 
atención sobre la inspiración "teleológica" de esa interpretación, interesada en convertir al liberalismo en "antecedente de una revolución democrática predestinada", a fin de ofrecer un pasado legítimo para el desafio de la segunda posguerra: la construcción de la democracia de masas. Para Antonio Annino y Rafaelle Romanelli, esa supuesta "predestinación" de la democracia descansaba sobre un vínculo de "necesidad más que histórico",(1) inaceptable desde el punto de vista heurístico. Un mayor respeto por las particularidades de cada proceso - apuntaba Romanelli al estudiar la formación del sistema político italianopermitiría comprender que no siempre la ampliación del sufragio implicó un avance en la senda hacia la democracia, ya que "en cuestiones de liberalismo, la experiencia nos enseña que ciertas extensiones son extensiones de elementos, no liberales, sino serviles, en las cuales encuentra alimento no la libertad, sino la tiranía administrativa y política y la corrupción".(2)

Desde una perspectiva divergente también Eric Hobsbawm ha reflexionado sobre esa "predestinación" de la democracia, apuntando que, aun cuando desde la década de 1870 la democratización fuese ya el escenario de la vida política - al margen de las preferencias de las clases gobernantes-, "el progreso de la política democrática entre 1880 y 1914 no hacía prever ni su permanencia ni su triunfo universal".(3) En efecto, para 1918 eran todavía escasos los países que habían adoptado el sufragio universal a rajatablas, y aun cuando las dos posguerras ofrecerían argumentos positivos para la fe democrática, cualquier observador situado en la década de 1930 hubiese extraído una conclusión desoladora.

Ese llamado de atención sobre la tardía difusión del sufragio universal, incluso en Occidente, tiende a reproducir para el siglo XX lo que para Annino y Romanelli constituye una paradoja de los historiadores al analizar el XIX: la de aceptar la existencia de una "civilización liberal" identificada con el "majority system" anglo-francés, aun cuando resulte posible comprobar la restricción de ese fenómeno "a casos aislados y poco numerosos". (4) La alternativa propuesta resulta atractiva: trascender el análisis de los rasgos aparentes de los modelos para internarse en el estudio de esa síntesis entre jerarquías sociales y valores políticos que habría constituido su clave, y sobre la cual se asentaba la eficacia y legitimidad de cada uno. Las "prácticas electorales en Irlanda y en la Inglaterra victoriana -afirman Annino y Romanelli- muestran que su legitimidad estaba arraigada en el mundo de las jerarquías sociales antes que en los valores del sistema político",(5) combinación que se repite en otros países donde hasta ahora se juzgaba que el liberalismo resultaba inaplicable, como los de la Europa Mediterránea o algunos países de América Latina. ${ }^{(6)}$

La revaluación del modelo político notabiliar permite asimismo poner en cuestión su pretendido carácter "restrictivo". Tanto Annino-Romanelli en sus consideraciones sobre el liberalismo europeo como Romanelli al estudiar el caso italiano relativizan los parámetros interpretativos rígidos que caracterizaron a los estudios tradicionales: "La inegalité liberal fundamental - sostienen - no debe buscarse en la distinción entre quién vota y quién no vota, sino en los procesos de cooptación subordinada - como por ejemplo los que pasan por la construcción política de las listas electorales-....Los notables son tales porque incluyen y no porque excluyen". (7) Sobre esta lectura argumentan en favor del carácter crecientemente "inclusivo" de tales sistemas en tanto resulta posible comprobar una lenta pero progresiva ampliación de su base electoral, resultante de una combinación artesanal entre exigencias formales, geometría electoral y clientelismo político. ${ }^{(8)}$

El carácter innovador de la lectura de Annino-Romanelli se pone de manifiesto en la confrontación con estudios anteriores disponibles, como por ejemplo el dedicado por José Varela Ortega a la España de la Restauración. También aquí nos encontramos dentro del 
área de los sistemas políticos latinos tradicionalmente cuestionados por sus "desviaciones". Sin embargo, preocupado por comprobar el desarrollo de un proceso de modernización y consolidación política, Varela Ortega descarta la asignación de roles a los notables dentro del nuevo sistema - expresión de un orden anterior-, quien es reemplazado por el cacique, "jefe político de una parcialidad local",(9) el cual no fundaba su poder en una jerarquía social sino en su capacidad de "manipulación parcial .......del aparato administrativo" dentro de un "régimen de soberanía parcelaria".(10)

A diferencia del estudio de Romanelli, donde un centro de reciente creación consigue articularse y expandirse progresivamente sobre periferias tradicionales que coadyuvan en la formación del nuevo régimen político aportando jerarquías y legitimidades propias, Varela Ortega pretende soslayar cualquier signo de continuidad,(11) intentando resolver la cuestión de la influencia de las periferias sobre el centro recurriendo a una lógica política que a menudo se revela demasiado moderna para su objeto de estudio. Esa intención le conduce incluso al punto de forzar a la autonomía política a trascender su carácter de elección teórica para presentarla como emergente de un análisis empírico, como puede comprobarse reiteradamente, por ejemplo, en el énfasis puesto por el autor en repetir que el poder en la España de la Restauración no residía en una clase - terrateniente ni industrial- ni tampoco se derivaba de la opinión pública. ${ }^{(12)} \mathrm{Si}$ a eso se le suma la existencia de una Iglesia expropiada, los privilegios estamentales abolidos y un Ejército prescindente, ${ }^{(13)}$ se termina por creer que para Varela Ortega el sistema liberal de la Restauración no necesitaba descansar sobre bases sociales ni económicas, ${ }^{(14)}$ o bien -lo que resulta más probable-, que ha elaborado una lectura ingenua a partir de la retórica y la proyectualidad modernizadora de los políticos de la época, desechando toda prueba en sentido contrario. ${ }^{(15)}$

Las coincidencias entre Varela Ortega y Annino-Romanelli parecen finalmente concentrarse en dos cuestiones básicas: la descripción de la composición del electorado de los sistemas liberales recurriendo a la figura de los meridianos - en lugar de la tradicional, sustentada en cambio sobre paralelos (los cuales permitían definir a las clases) -, resultado de la práctica del clientelismo político, y la identificación de sus límites en un crecimiento súbito e incontrolable del electorado. Sin embargo, también en este caso notables y caciques afrontan la ampliación del sistema respondiendo a lógicas distintas. (16) En tanto para Annino-Romanelli - como se ha indicado- los "notables son tales porque incluyen y no porque excluyen", para Varela Ortega las posibilidades de reproducción del sistema caciquil habrían descansado sobre una limitación de privilegios y favores en una clientela estrecha, dependiente de la concesión de beneficios extraordinarios. (17)

\section{Sociabilidad política y sufragio universal}

Tan lejos de una lectura événementiel como de privilegiar la continuidad aplicando una mirada de larga duración - como, por ejemplo, la de Alexis Tocqueville en El Antiguo Régimen y la Revolución-(18) también los estudios recientes sobre sociabilidad política se han esforzado por reconstruir esa sutil e irrepetible combinación entre valores y prácticas antiguos y modernos que parecen encubrir los procesos de formación de los sistemas políticos decimonónicos. Para ello ha resultado indispensable comenzar a desbrozar un canon de interpretación diseñado sobre la base de una rica proyectualidad característica del liberalismo fundacional - a menudo en contextos transicionales traumáticos - que, relativi- 
zando sus condiciones históricas, tendió a estilizar sus generosas expectativas recortándolas sobre una representación del pasado caprichosamente descalificadora.

En esa dirección se interna por ejemplo Maurice Agoulhon al preguntarse sobre el significado de la República como forma de poder. ${ }^{(19)}$ Sus primeros argumentos apuntan a decodificar el proceso iniciado con la Revolución del 48 en los términos de la de 1789 , constatando la existencia inicial de un nuevo clima de ideas ampliamente favorable para la redención y transformación radical del mundo "egoísta e injusto" del censo. Los agentes designados para ello no serían otros que las clases postergadas, a las cuales la sanción del sufragio universal otorgaba en este momento su pasaporte de ingreso al mundo político. Sin embargo, advierte Agoulhon, en pocas semanas ese razonamiento tendría oportunidad de demostrar su inconsistencia: la naciente sociabilidad republicana sería ante todo el resultado de una síntesis de valores y prácticas, a menudo contradictorios, que en gran medida permanecería ocluida o bien deformada tras las descripciones del afiebrado proceso epilogado por la funuación del Segundo Imperio.

En efecto, el estudio de la sociabiliclad política en la República del 48 le permite, por una parte, comprobar la permanencia de ciertas prácticas y roles, expresada por ejemplo en el protagonismo que, en pleno auge republicano, conservaría el notable local - no sólo en el caso del Partido del Orden sino incluso en la mismísima Montaña, sin que ello implicase una contradicción del perfil progresista e idealista autoasignado-, o el aprovechamiento de la experiencia electoral acumulada por los sectores medios $-y$ los sustratos más altos de las clases populares- durante la Monarquía de Julio, iniciada gracias a la sustancial rebaja del censo para las elecciones municipales registrada a partir de 1831. Simultáneamente Agoulhon verifica el desarrollo de una nueva sociabilidad vinculada a la contienda electoral, cuyas expresiones más características serían el asociacionismo, la lectura colectiva, la proliferación de impresos, una renovada iconografía (por ejemplo, las célebres "marchas hacia las urnas"), etcétera. De este modo, aun cuando esta sociabilidad "moderna" haya sido considerada tradicionalmente como "base de materialidad" de un nuevo imaginario republicano, aplicado a la fundación de una nueva legitimidad basada en la negación del orden precedente $-y$, según propone Pierre Rosanvallon, ${ }^{(20)}$ en la confrontación entre valores republicanos y monárquicos-, una perspectiva centrada en el estudio de la sociabilidad o las prácticas políticas como la desarrollada por Agoulhon conduciría en cambio a caracterizar al emprendimiento del ' 48 como una articulación incipiente entre innovación y continuidad, cuya reproducción pendería de la capacidad de sus clases dirigentes para consolidar ese equilibrio en clave republicana.

Sin embargo, la aceleración de la dinámica del proceso a partir del recorte del sufragio universal de 1851 y su más contundente secuela, la puesta en marcha de un nuevo sueño imperial encabezado por un personaje tragicómico como Luis Napoleón III, permite poner en cuestión esta última afirmación. ¿Era este desenlace un producto de la incapacidad de la dirigencia republicana para realizar esa síntesis, o bien, como interpretaba Karl Marx, se trataba de una "traición de la burguesía", necesitada de una centralización política que acabase con la inestabilidad que el "gobierno propio" había producido, para dedicarse a explotar tranquilamente los frutos de su victoria como clase?(21) Agoulhon desecha la lectura de Marx con argumentos endebles. Sin embargo, tras la disputa teórica que sirve de parteaguas entre ambos parece dibujarse un escenario similar, delineado en torno de las reticencias y temores que el sufragio universal provocó en la dirigencia política y las clases dominantes francesas en 1848 , los cuales se repetirían en 1871, en vistas de la contundente experiencia de la Comuna. 
Pierre Rosanvallon aborda el estudio de esa reacción apuntando que, a diferencia de los años 1830 y 1840, cuando "los republicanos tenían otras preocupaciones en la cabeza. Debían combatir para abolir el censo antes de pensar en las condiciones de un ejercicio razonable de la soberanía",(22) la sanción del sufragio universal auspiciaría la configuración de un horizonte de ambigüedades. Sin embargo, desde un primer momento las clases dirigentes habrian asumido el desafio de proteger a la República de la "inmadurez" de las masas sin mellar su legitimidad, esto es, limitar la capacidad acordada a las clases "rezagadas e ignorantes" - y que ahora juzgaban como "inoportuna"-, ${ }^{(23)}$ sin dañar con ello el principio de soberanía del pueblo sobre el que descansaba el nuevo sistema. Ese desafio excedia con mucho a la Francia Republicana, pudiendo ser suscripto sin mayores objeciones por todo un liberalismo decimonónico caracterizado por impulsar la existencia de constituciones $\mathrm{y}$ asambleas soberanas elegidas, para luego tratar por todos los medios de esquivarlas actuando de forma antidemocrática - como apunta ajustadamente E. Hobsbawm-. (24) Para el caso francés, Rosanvallon cree reconocer la clave de la solución en el consenso alcanzado entre republicanos y conservadores tras largos años de debate acerca del establecimiento de un orden jerárquico dual: por un lado, entre niveles del sufragio, y por otro, entre los términos de la "tensión" intrínseca del pensamiento democrático, la calificación y el número. ${ }^{(25)}$

En el primer caso, Rosanvallon reconstruye el proceso a través del cual el sufragio-expresión de la soberanía popular sería ungido como "arca santa" de la democracia, en detrimento del sufragio-acompanamiento - es decir, el sufragio como procedimientoque, como contrapartida, resultaría subordinado y enajenada su capacidad de "efectuar ningún acto de soberania".(26) El establecimiento de este orden habría de repercutir directamente en la resolución de la "tensión democrática", ya que en adelante la legitimidad sólo podría "pertenecer a la verdadera razón, encarnada en la institución republicana fundada sobre la negación de un pasado metafísico y teocrático".(27) En este punto sería necesario ir todavía un paso más allá, intentando sobre estas nuevas bases la reconciliación de la razón con el número, restaurando la equidad del sistema de manera artesanal. Para ello, luego de un debate tan complejo como apasionado, la dirigencia francesa estaría en condiciones de lanzar en 1882 una verdadera "cruzada demopédica", sobre la base de la ley del 22 de octubre - que instituía la escolaridad gratuita y obligatoria-, garantizando así teóricamente una racionalidad mínima de los votantes.

Sin embargo, esa equidad sería sólo aparente: tras su fachada demopédica el sistema educativo implementado respondía a una matriz deferencial ${ }^{(28)}$ que, junto con la escolarización obligatoria de las masas, se preocupaba en construir nuevas jerarquías sociales, a la "altura de los tiempos". A esto respondía, efectivamente, el proyecto de formación de "una nueva 'cabeza de pueblo' ", (29) emergente de una sociedad que comenzaba a privilegiar las capacidades, en sustitución de los órdenes, cuerpos o clases, requiriendo para ello el forjamiento de una herramienta fabulosa: la Universidad francesa. La implementación de una perspectiva de racionalización social de inspiración fisiocrática, profundamente vertical y elitista, constituyó seguramente la síntesis más satisfactoria que las clases dirigentes francesas pudieron brindarse ante la amenaza de la democracia y el sufragio universal a través de un siglo de debates. En virtud de eso, y aun cuando el interrogante central no hubiera variado, las reflexiones de Alexis de Tocqueville en los años 30, prescribiendo la "doble vuelta electoral" como el mejor reaseguro para la cualidad ante los temidos efectos del número, ${ }^{(30)}$ parecían cubrirse de ingenuidad y obsolescencia ${ }^{(31)}$ ante la contundencia de los resultados de la aplicación de los aportes científicos a la manipulación de las masas, 
provistos por las nuevas disciplinas fundadas sobre esa preocupación, como la sociología o la psicología social.

\section{La democracia "deferencial"}

En opinión de Rosanvallon, la solución diseñada por las clases dirigentes francesas concluía por consagrar a la democracia como una especie de "régimen de sanción popular", en el cual el sufragio universal quedaba reducido al carácter de poder negativo -capacidad de veto- ${ }^{(32)}$ Annino-Romanelli extienden esa caracterización al conjunto del liberalismo decimonónico, al que designan, recuperando la definición de Bagehot de 1929, como "una 'democracia deferencial', un sistema que debe lograr expresar un consenso colectivo con la idea de que la opinión de algunos debe valer más que su peso numérico".(33) E. Hobsbawm prescinde de una definición general, aun cuando recuerda la elaborada por Lenin en 1917: "Una república es la mejor concha política para el capitalismo y, en consecuencia, una vez que el capitalismo ha conseguido el control de esa concha .......asienta su poder de forma tan segura y tan firme que ningún cambio, ni de personas ni de instituciones, ni de partidos en la república democrático-burguesa puede quebrantarla".(34) Para el sistema parlamentario del Imperio Alemán, Gunter Roth apunta como impedimento principal para la realización de "los objetivos últimos sociales y democráticos", la "peculiar combinación de políticas represivas y permisivas" dispuesta por un estado que designa como autoritario. ${ }^{(95)}$

Entre la realidad que se proponen reconstruir estas interpretaciones y la de aquellos sistemas basados en la articulación artesanal entre un centro innovador de matriz crecientemente republicana y periferias tradicionales de base notabiliar o caciquil estudiados por Romanelli, Agoulhon y Varela Ortega, las distancias resultan enormes. Durante la segunda mitad del siglo, y como resultado de la expansión de las relaciones capitalistas y el sorprendente crecimiento económico, las bases fundamentales de estos sistemas - la pervivencia de una dimensión local de la vida política, con legitimidad y jerarquías propias, y un ejercicio poco difundido de la capacidad de sufragar-, no tardarían en derrumbarse. En tanto el debate sobre el sufragio universal ya ha sido considerado, resulta de interés recordar esa especie de epitafio para el sistema liberal-notabiliar escrito por Emile Durkheim en el Prefacio a la segunda edición de La división del trabajo social:

"El espíritu provincial desapareció sin remedio; el patriotismo de campanario se volvió un arcaísmo que no se puede restaurar a voluntad. Los asuntos municipales o departamentales no nos tocan y apasionan ya más que en la medida en que coinciden con nuestros asuntos profesionales". ${ }^{(36)}$

La reflexión de Durkheim introduce su propuesta de organización para el sistema político en una Francia donde la industrialización habría conducido a un estado de "anomia" social. Eso planteaba un nuevo dilema acuciante para las clases dirigentes y los intelectuales, que podría formularse en los siguientes términos: ¿cómo garantizar la cohesión social en una sociedad en transformación, en la que las masas urbanas e industriales que ingresaban a la política habían abandonado sus lealtades locales - características del sistema liberal-notabiliar-, sin encontrar en su tradición ni en su propia experiencia razón alguna para reconocer como legítima la autoridad del Estado Nacional? 
La solución adoptada - como hemos visto- reconocía en la extensión del sufragio "negativo" y la democratización en el acceso a la educación básica herramientas maestras, al punto de obligar a la oposición más extrema a subordinarse mansamente a los requerimientos del sistema. En cuanto al sufragio universal, los dirigentes socialistas consintieron en modificar su caracterización crítica, sobreponiéndose a sus temores de terminar siendo "engullidos por el sistema", luego de contrapesar las grandes posibilidades de superar su característico aislamiento que prometía la urna de votación. ${ }^{(37)} \mathrm{El}$ acceso a la educación "burguesa", por su parte, había constituido un reclamo secular, por lo cual no mereció mayores objeciones.

No serían éstos, de todas formas, los únicos mecanismos de cooptación habilitados. Según apunta E. Hobsbawm, la sociedad de masas vino acompañada del "descubrimiento comercial del mercado de masas y los espectáculos de masas. La industria de la publicidad alcanza en ese momento mayoría de edad". (38) El nuevo escenario de lo público exigía el desarrollo de una retórica desesperada por agradar a esas masas, caracterizada por su alto nivel de demagogia y chauvinismo: "En lo sucesivo, los que gobernaban podrían decir lo que pensaban únicamente amparados por la oscuridad de los pasillos del poder, los clubes, las reuniones sociales privadas, partidas de caza o casas de campo de fin de semana donde se reunían los miembros de la élite, muy lejos de los falsos enfrentamientos de los debates parlamentarios y los mitines públicos. Así, la era de la democratización se convirtió en la era de la hipocresía pública, o más bien de la duplicidad".(39)

Esa duplicidad no parece haber estado identificada con ningún partido o clase en particular, sino que comenzaba a revelarse como una característica de la democracia de masas. Roth, por ejemplo, adjudica la "aparente incongruencia entre la teoría y la práctica" de la socialdemocracia alemana -ideología radical y práctica moderada-, a la "situación estratégica en la que se encontraba el movimiento obrero (que) lo hizo abrazar al mismo tiempo que mitigar el radicalismo de la teoria marxista". (40)

Amparadas por una política imperialista de amplia repercusión entre las masas -cuyo éxito, por ejemplo, forzaria a la socialdemocracia alemana a "adaptarse a las tendencias nacionalistas más fuertes en la opinión pública"-, ${ }^{(41)}$ las nuevas democracias de masas emprendieron una empresa de "creación de la tradición", desarrollando una simbología que privilegió los valores y sentimientos nacionalistas. La piedra angular de esa construcción residiria, una vez más, en una adecuada síntesis entre continuidad e innovación, entre el presente y el pasado heroico que en cada caso resultara disponible - por ejemplo la Corona, la Revolución, la República, la gloria militar, etcétera-.(42)

En opinión de E. Hobsbawm, las democracias que sucedieron a los sistemas liberal-notabiliares demostraron una creciente heterogeneidad, sin haber respondido a "ningún modelo político nítido". (43) Sin embargo, tanto su carácter deferencial, como una manifiesta vocación manipulativa asumida por las élites -incluso las pertenecientes a los partidos o fuerzas de la izquierda opositora, que habian alcanzado una estructura masiva al precio de terminar "engullidos" finalmente por el sistema-y un desprecio por la profundización del debate ideológico permiten identificar puntos ciertos de encuentro.

Habiendo accedido mediante trayectos irregulares al sufragio universal, los nuevos ciudadanos serían lanzados a la vida pública provistos de la poco gratificante calificación de "masa", interpelados por Estados y partidos que privilegiaban la estabilidad de la organización, desoyendo sus cuestionamientos e inquietudes. El "sufragio-acompañamiento" se imponía así sólo después de haber sido despojado de su carácter de expresión de una soberanía popular que era ahora detentada por las élites. incluso comn nhistn te Hahste 
político-intelectual, como lo demostraban los novedosos - y numerosos- estudios sobre la clase política producidos en este momento por Ostrogorski, Paretto, Mosca y Michels, entre otros. ${ }^{(44)}$ De este modo, al estallar la Primera Guerra Mundial, las condiciones efectivas sobre las cuales la democracia política era posible resultaban bastante modestas, en tanto el anhelo de la democracia social continuaba perteneciendo al terreno de las utopías.

\section{Notas}

(1) A. Aninno, R. Romanelli, "Nota preliminar", en: Notabili, Elettori, Elezioni, Quaderni storici, Nuova Serie, 69, diciembre 1988, pág. 2.

(2) R. Romanelli, "La regole del gioco. Note sull'impianto del sistema elettorale in Italia (1848-1895)", en: Quaderni storici, N²69, op. cit., pág. 17.

(3) Eric Hobsbawm, La Era del Imperio, Labor, Madrid, 1989, pág. 112.

(4) A. Aninno, R. Romanelli, op. cit., pág. 2.

(5) Ibídem.

(6) Para América Latina, consultar una excelente compilación de estudios históricos en: Antonio Annino (coord.), Historia de las elecciomes en Iberoaménica, siglo XIX. De la formación del espacio político nacional, FCE., Buenos Aires, 1995.

(7) Idem, pág. 4.

(8) Los "notables proceden como cooptando sucesivamente a nuevos segmentos de la sociedad dentro del cuerpo electoral según ritmos definidos más que por las evoluciones ideológicas por contingencias de mediano plazo y todo siempre dentro de esquemas precisos de control". Ibídem, pág. 4. En este contexto - sostiene A. Annino-, América Latina afrontó durante el siglo XIX un desafio "insólito" "Mientras que en los demás países occidentales las élites tuvieron que experimentar paulatinamente una mayor difusión del voto y una expansión de la ciudadania para garantizar la gobernabilidad, el camino latinoamericano fue muy diferente ya que desde el primer momento el cuerpo electoral fue muy amplio, y en esto radica la fuerza de las autonomías locales. El gran problema de las élites no fue cómo ampliar el universo de los votantes sino cómo encauzar la dinámica electoral hacia el centro y así solucionar los graves problemas de la gobernabilidad". A. Annino, "Introducción", en: Historia de las elecciones en Iberoamérica, siglo XIX. De la formación del espacio polático nacionah op. cit., pág. 13.

Agradezco los comentarios de Alejandro y Fabián Herrero sobre las particularidades de los procesos latinoamericanos dentro del "modelo occidental" y de la necesidad de llamar la atención al respecto en esta comunicación.

(9) J. Varela Ortega, Los amigos políticos. Partidos, elecriomes y cariquismo en la restauración (1875-1900), Alianza, Madrid, 1977, pág. 212.

(10) Idem, pág. 354.

(11) "No parece, pues, que la sociedad española de la segunda mitad del siglo XIX fuera una prolongación de las estructuras semifeudales del Antiguo Régimen. Más bien se trataba de una sociedad burguesa del Mediterráneo europeo, ruralizada, burocratizada y subdesarrollada". Idem, pág. 204.

(12) Para Varela Ortega “.....la fuente del poder político no se encontraba en los terratenientes como clase. Y, sin embargo, tampoco estaba en manos de los grupos industriales". (pág. 212) A su juicio, se trataba de un "régimen donde la fuerza política no se derivaba de la opinión".(pág. 269) Ni los liberales, ni los conservadores, ni los republicanos "pretendian en sus campañas electorales conquistar el favor de la opinión pública ni dependían de intereses colectivos, sino que competían por el mismo patronazgo". Idem, pág. 243. 
(13) "Las leyes liberales no fueron papel mojado; marcaron una ruptura bien clara. La unificación e igualdad legislativas trasladaron poder a la burocracia estatal, aboliendo privilegios locales y estamentales a expensas de la Iglesia y la nobleza. Una administración muy crecida y centralizada creó una burguesía de servicios e impulsó la concentración urbana. El Ejército quedó nacionalizado, al romper con privilegios aristocráticos en el reclutamiento ....... po parece, pues, que la sociedad española de la segunda mitad el siglo XIX fuera una prolongación de las estructuras semifeudales del Antiguo Régimen. Más bien se trataba de una sociedad burguesa del Mediterráneo europeo, ruralizada, burocratizada y subdesarrollada". Idem, pág. 207.

(14) "El enfrentamiento se produjo entre la clase política en control de un Estado considerado ineficiente y ciertos grupos que no se percibían como dueños de ese Estado pero si con derecho a serlo". Idem, pág. 214.

(15) El siguiente razonamiento resulta sumamente indicativo de esa determinación: "La protección terminó por imponerse; pero no la trajo la presión de una oposición organizada en asociaciones económicas. Los políticos caciquiles triunfaron donde los regeneracionistas habian fracasado. ......uno se siente inclinado a pensar que el programa proteccionista ni se impuso en la derecha Liberal por presión de la opinión pública, ni al dictado de los terratenientes como grupo. Esto no significa que detrás de ese - u otro- programa de alcance general no hubiera opinión ni que dejara de favorecer a determinada clase. Quiere decir simplemente que ese programa no se expresó como mandato electoral ni se impuso por la presión de los intereses sociales y económicos afectados actuando colectivamente. Es probable que la opinión fuera proteccionista, pero ello no forzó a los políticos en esa dirección". Idem, pág. 280.

(16) Si bien Romanelli reconoce "una posible variante del modelo notabilar: aquí una acción unánime involucra a una comuna en particular en apoyo de un candidato cuyo carisma no está asociado tanto a la posesión de bienes cuanto al uso desprejuiciado del aparato administrativo", su comportamiento no parece responder responder a características similares a las enunciadas por Varela Ortega. Cf. R. Romanelli, "La regole...", op. cit., pág. 29.

(17) El "control (del cacique) no se mide en términos de opinión; por el contrario, se realiza en medio de la desmoralización general repartiendo beneficios divisibles entre un pequeño núcleo de seguidores". J. Varela Ortega, Los amigos..., op, cit., pág. 354.

(18) Alexis de Tocqueville, El antiguo régimen y la revolución, Alianza, Madrid, 1982, 2. vol.

(19) M. Agoulhon, 1848 ou l'aprentissage de le Reprublique - 1848-1852, Ed. du Seuil, Paris, 1973.

(20) P. Rosanvallon, Le sacre du citoyen. Histoire du suffrage universel en France, Gallimard, Paris, 1992, pág. 4. (21) "Cuando en cada manifestación de vida de la sociedad veía un peligro para la 'tranquilidad', ¿cómo podía empeñarse (la burguesía) en mantener a la cabeza de la sociedad el régimen de la intranquilidad, su propio régimen, el régimen parlamentario, este régimen que, según la expresión de uno de sus oradores, vive en la lucha y merced a la lucha? El régimen parlamentario vive de la discusión, ¿cómo, pues, va a prohibir que se discuta? .....El régimen parlamentario lo deja todo a la decisión de las mayorías; ¿cómo, pues, no van a querer decidir las grandes mayorías fuera del Parlamento? Si los que están en las cimas del Estado tocan el violín, ¿qué natural sino que los que están abajo bailen?

Por tanto, cuando la burguesía excomulga como 'socialista' lo que antes ensalzaba como 'liberal', confiesa que su propio interés le ordena esquivar el peligro de su Gobierno propio, que para poder imponer la tranquilidad en el país tienen que imponérsela ante todo a su Parlamento burgués, que para mantener intacto su poder social tiene que quebrantar su poder político; que los individuos burgueses sólo pueden seguir explotando a otras clases y disfrutando apaciblemente de la propiedad, la familia, la religión y el orden bajo la condición de que su clase sea condenada con las otras clases a la misma nulidad política; que, para salvar la bolsa, hay que renunciar a la corona, y que la espada que había de protegerla tiene que pender al mismo tiempo sobre su propia cabeza como la espada de Damocles". K. Marx, El Dieciocho Brumario de Luis Bonaparte, Col. Austral, Ed. Espasa-Calpe, Madrid, 1992, págs. 25960.

(22) P. Rosanvallon, Le sacre du citoyen..., op. cit., pág. 11.

(23) Ibídem.

(24) Eric Hobsbawm, La Era del Imperio, op. cit., pág. 86. 
(25) Este tránsito hacia la convergencia tiene como punto de partida para Rosanvallon una distancia en los diagnósticos y valoraciones de republicanos y conservadores que parece descansar más en los matices que en la naturaleza de las cuestiones en debate. Esta lectura se enfrenta con la mucho más esquemática formulada por Agoulhon, quien postulaba la coexistencia de dos representaciones contrapuestas de la república: la de los "verdaderos" hombres del 48 , ideal y de contenidos máximos y la de los conservadores, real y de contenidos mínimos.

(26) P. Rosanvallon, Le sacre du citoyen..., op. cit., pág. 4. Para Rosanvallon, su transcripción iconográfica corresponde al reemplazo de la tradicional representación de la democracia del 48, como "marcha hacia las urnas", por la poderosa y desafiante del león en los 70, marcando el tránsito de la igualdad de derechos a la estabilidad e intimidación.

(27) Ibídem.

(28) Agradezco los comentarios de Luis Alberto Romero sobre esta cuestión.

(29) P. Rosanvallon, Le sacre du ciloyen..., op. cit., pág. 15.

(30) Alexis. de Tocqueville, La Democracia en América, Alianza, Madrid, 1982, 2 vols.

(31) A punto tal de quedar prácticamente excluido de los estudios de teoría política más de medio siglo.

Cf. Giovanni Sartori, Teoria de la Democracia, Rei, Buenos Aires, 1987, 2 vols.

(32) P. Rosanvallon, Le sacre du citoyen..., op. cit., pág. 15.

(33) A. Annino, R. Romanelli, "Nota...", op. cit., pág, 6.

(34) Eric Hobsbawm, La Era del Imperio, op. cit., pág. 111. “Asi, pues, las clases dirigentes optaron por las nuevas estrategias, aunque hicieron todo tipo de esfuerzos para limitar el impacto de la opinión y del electorado de masas sobre sus intereses y sobre los del Estado, así como sobre la definición y continuidad de la alta política". Idem, pág. 102.

(35) G. Roth, The social democrats in Imperial Germany. A study in working class social isolation and national integration, Totowa, New Jersey, 1963, pág. 6.

(36) E. Durkheim, La división del trabajo social, Planeta-Agostini, Barcelona, 1985, t. I, págs. 1 y ss.

(37) Cf. G. Roth, op. cit., pág. 30.

(38) Eric Hobsbawm, La Eru del Imperio, op. cit., pág. 108.

(39) Ibídem, pág. 89.

(40) G. Roth, op. cit., pág. 6.

(41) Idem, pág. 38. Roth agrega que los "triunfos de Bismark y del ejército prusiano constituian obstáculos gigantescos a sus aspiraciones democráticas y socialistas".

(42) Cf. Eric Hobsbawm, La Era del Imperio, op. cit., pág. 102.

(43) Idem, pág. 99.

(44) Cf. G. Roth, op. cit. 